\title{
PIERRE DUQUESNE 1925-2003. ONTWERPER VAN BEHANGPAPIEREN IN DE USINES PETERS-LACROIX TE HAREN (1947-1979), KUNSTENAAR TE DIEGEM
}

\section{Inge Misschaert}

Musées et Archives de la Ville de Bruxelles | «Cahiers Bruxellois - Brusselse Cahiers »

2021/1 LII | pages 361 à 382

ISSN 1784-5157

DOI 10.3917/brux.052.0361

Article disponible en ligne à l'adresse :

https://www.cairn.info/revue-cahiers-bruxellois-2021-1-page-361.htm

Distribution électronique Cairn.info pour Musées et Archives de la Ville de Bruxelles.

(C) Musées et Archives de la Ville de Bruxelles. Tous droits réservés pour tous pays.

La reproduction ou représentation de cet article, notamment par photocopie, n'est autorisée que dans les limites des conditions générales d'utilisation du site ou, le cas échéant, des conditions générales de la licence souscrite par votre établissement. Toute autre reproduction ou représentation, en tout ou partie, sous quelque forme et de quelque manière que ce soit, est interdite sauf accord préalable et écrit de l'éditeur, en dehors des cas prévus par la législation en vigueur en France. Il est précisé que son stockage dans une base de données est également interdit. 


\section{PIERRE DUQUESNE 1925-2003. ONTWERPER VAN BEHANGPAPIEREN IN DE USINES PETERS-LACROIX TE HAREN (1947- 1979), KUNSTENAAR TE DIEGEM ${ }^{1}$}

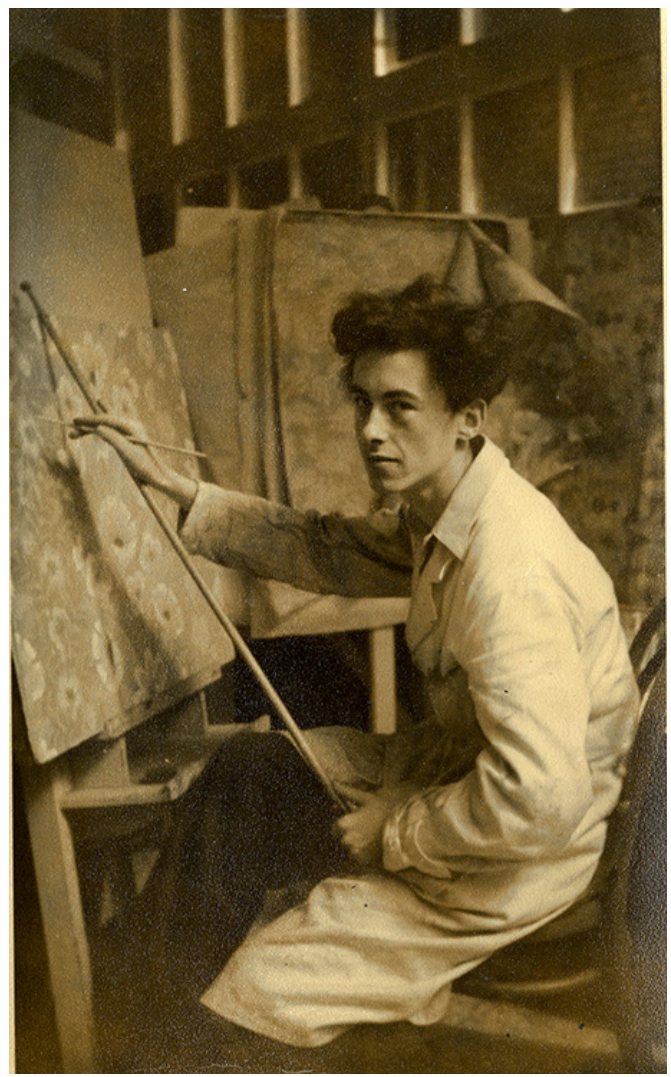

Afbeelding 1: Pierre Duquesne in het atelier van UPL. Bron foto: Archief van de Stad Brussel, Sectie Privéarchief, Particuliere archieven, Archives Pierre Duquesne, n¹228_01.

1. Dit onderzoek werd gevoerd in het kader van mijn Bachelorproef binnen de Kunstwetenschappen aan de universiteit van Gent, begeleid door Prof. Dr.M. Sterckx. 


\section{Een kleine schakel in een groter geheel}

Pierre Duquesne (1925-2003) was als ontwerper meer dan dertig jaar actief bij de bekende behangpapierfabriek, de Usines Peters-Lacroix, kortweg UPL, in Haren in de periode 1947-1979². In 2015 werd zijn privé-archief, dat voornamelijk uit brieven, foto's en 1050 kunstwerken bestaat, door zijn zoon Stéphane Duquesne aan het stadsarchief van Brussel geschonken. ${ }^{3}$ Hoewel dit archief voor het grootste gedeelte bestaat uit kunstwerken die Pierre Duquesne buiten zijn werkuren in de fabriek maakte, bevinden zich in de brieven en foto's tal van verwijzingen naar zijn functie en carrière als ontwerper van behangpapier. Pierre Duquesne is een voorbeeld van een ontwerper en kunstenaar die gedurende zijn hele carrière op dezelfde dunne grens balanceert als veel andere kunstenaars. Niet zo bekend als Victor Servranckx (1897-1965) en René Magritte (1898-1967) die slechts enkele jaren en op uitdrukkelijk verzoek bij de Usines Peters-Lacroix werkten ( $c f$. infra), zet Pierre Duquesne zich jarenlang als anonieme ontwerper in binnen het creatieve ontwerpteam voor dit bedrijf. ${ }^{4} \mathrm{Na}$ de werkuren maakt hij talloze tekeningen, schilderwerken en een aantal beeldhouwwerken. ${ }^{5}$ In de databank van het KIK/IRPA bevindt zich een foto van Pierre Duquesne, aan het werk in het atelier van de UPL, die door dit onderzoek geïdentificeerd kon worden (zie afb. 2). ${ }^{6}$

2. "Usines Peters-Lacroix," laatst geraadpleegd op 20 mei 2018, http://www. odis.be/hercules/search2.php?searchMethod=simple\&search=usines\%20peters\%20 lacroix.

3. "Archief Stad Brussel," laatst geraadpleegd op 24 mei 2018, https://www.brussel. be/archief.

4. "Usines Peters-Lacroix," laatst geraadpleegd op 20 mei 2018, http://www. odis.be/hercules/search2.php?searchMethod=simple\&search=usines\%20peters $\% 20$ lacroix.

5. Stéphane Duquesne, e-mail met vragenlijst in bijlage aan Inge Misschaert, 23 maart 2018.

6. "Koninklijk Instituut voor het kunstpatrimonium," laatst geraadpleegd op 19 mei 2018, http://pp.kikirpa.be/gloss/index.php?tema=935. 


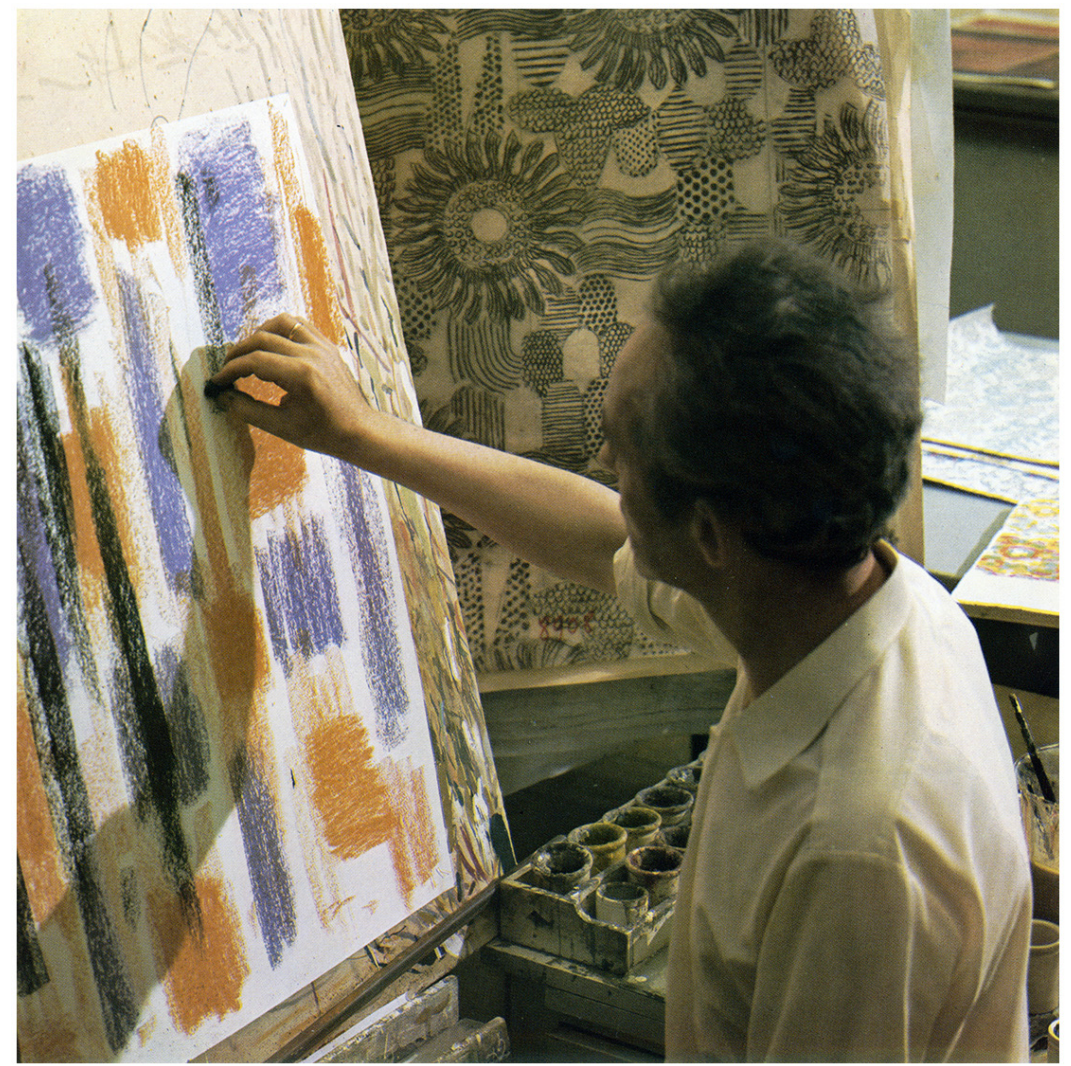

Afbeelding 2: Pierre Duquesne in het atelier van UPL. Bron foto: Usines Peters-Lacroix, (1883-1983), p. 39.

De laatste twintig jaar zorgt gesystematiseerd onderzoek naar behangpapier en de productie in ons land ervoor, dat de hiaten langzaam maar zeker opgevuld kunnen worden. ${ }^{7}$ De opsporing en bestudering van het bronmateriaal is daarbij erg belangrijk. Privé-archieven als dat van Pierre Duquesne zijn van groot belang, zoals blijkt uit de brief van Philippe de Fabry aan Stéphane Duquesne. ${ }^{8}$ Hij benadrukt terecht

7. Tentoonstelling 'Stemmen uit het behang: vier eeuwen geschiedenis van het behangpapier', in de ASLK-galerij te Brussel van 21 februari tot 18 mei 1997. Publicatie: Jacqué, Bernard, Geert Wisse en Daniël Verhoeven, Stemmen Uit Het Behang: Vier Eeuwen Geschiedenis Van Het Behangpapier (Brussel: ASLK, 1997).

8. Philippe de Fabry, brief aan Stéphane Duquesne n.a.v. het ontvangen van de catalogus, 24 september 2014. 
hoe zeldzaam en waardevol zulke persoonlijke getuigenissen over de werking van een fabriek zijn. Bovenal biedt de studie van behangpapier een boeiend overzicht van de evolutie van de smaak en de mentaliteit in een maatschappij. ${ }^{9}$

\section{De Usines Peters-Lacroix}

Een van de bekendste manufacturen van behangpapieren in België was UPL of de Usines Peters-Lacroix. In 1867 kocht de jonge zakenman Alphonse Lacroix (1845-1877) in Laken een atelier om behangpapier met de plaat te bedrukken. ${ }^{10}$ Hij gebruikte daarvoor niet de al sinds 1826 gebruikte mechanische techniek ${ }^{11}$, maar koos voor een meer ambachtelijke en traditionele manier van houten drukblokken ${ }^{12}$. Daardoor kreeg het behangpapier een hogere kwaliteit dan het mechanisch gedrukte behangpapier. Ook al werkten veel bedrijven consequent met het veel goedkopere gedrukte papier, in Laken zwoer men bij het ambachtelijke principe. Dit principe was helaas niet lang vol te houden. Om het bedrijf in de markt te houden, deed de mechanisatie in 1872 haar intrede. ${ }^{13}$ Deze datum wordt ook gezien als de effectieve begindatum van de Usines Lacroix. Helaas kwam het twee keer tot een zware brand in het bedrijf: in 1883 en in 1901. Beide calamiteiten werden overwonnen en het bedrijf herrees elke keer weer uit de as. $\mathrm{Na}$ de brand van 1883 werd het bedrijf op grondgebied

9. Françoise Marneffe, 'Le Papier Peint Sort De Ses Rouleaux', in: les Cahiers de la Fonderie, Bruxelles Hier, nr. 41; (Bruxelles industrielles hier, december 2009), 56. 10. Jan Van den Eynde, 'Les Usines Peters-Lacroix (UPL)', in: Malacha, Heemkunde Machelen (Vlaams Brabant). Jrg. 1, nummer 2, december 2004. Françoise Marneffe, 'Les Usines Peters-Lacroix à Haren', in: les Cahiers de la Fonderie, Bruxelles Hier, nr. 41; (Bruxelles industrielles hier, december 2009), 67. Truillet, J. 'De van Gelder à UPL; éléments pour une histoire de l'industrie du papier peint dans la région de Bruxelles', Les Cahiers de la Fonderie nr. 41; (Bruxelles industrielles hier, december 2009), 62.

11. s.n. Usines Peters-Lacroix, Paris UPL, Usines Peters-Lacroix, (1883-1983)(Paris: UPL, 1983), 16-18.

12. Françoise Marneffe, 'Les Usines Peters-Lacroix à Haren', in: les Cahiers de la Fonderie, Bruxelles Hier, nr. 41; (Bruxelles industrielles hier, december 2009), 67.

13. s.n. Usines Peters-Lacroix, Paris UPL, Usines Peters-Lacroix, (1883-1983)(Paris: UPL, 1983), 18. 
Haren weer opgebouwd en in 1884 in gebruik genomen. Ook na de brand in 1901 werd alles weer heropgebouwd om daarna weer verder te gaan met de productie. ${ }^{14}$

$\mathrm{Na}$ de dood van Alphonse Lacroix in 1877 zette de weduwe met haar vijf kinderen de zaak verder. ${ }^{15}$ In 1879 hertrouwde ze met Herman Peters, die al bij het bedrijf betrokken was. De oudste zoon, Georges Lacroix, ging op 15-jarige leeftijd in het familiebedrijf aan de slag. Van hem rest nog een tekening die hij maakte van de gebouwen van de Usines Peters-Lacroix, Société Anonyme (zie afb. 3). ${ }^{16}$

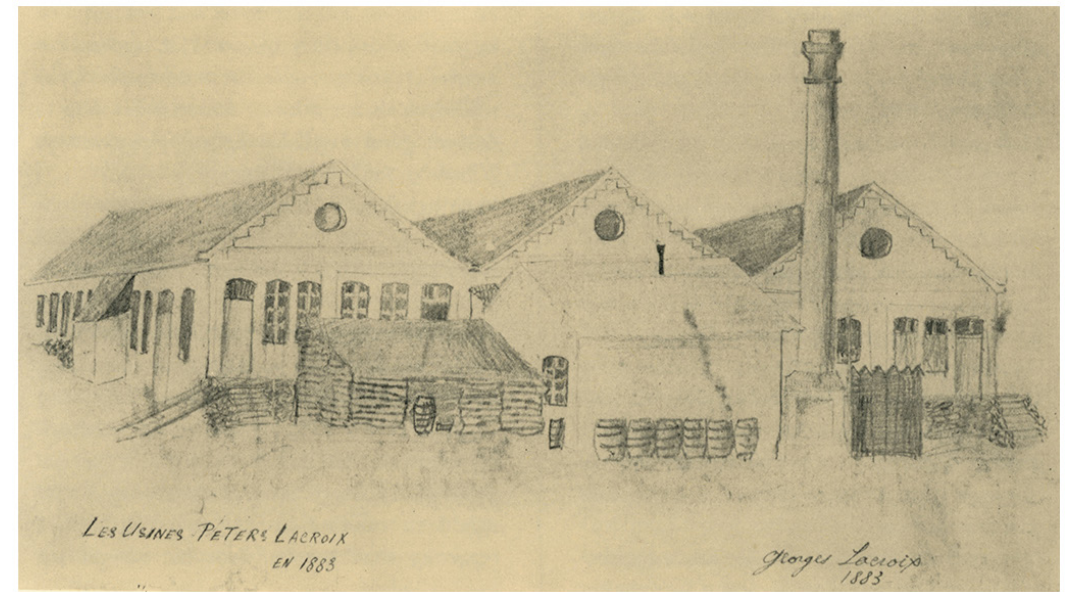

Afbeelding 3: Tekening van de fabriek door Georges Lacroix.

Bron foto: Usines Peters-Lacroix, (1883-1983), p. 17.

Samen met Yvan Peters, een halfbroer uit het tweede huwelijk, nam Georges in 1903 de leiding van het bedrijf op zich. De mechanisering breidde nog meer uit en innovatieve technieken werden ingevoerd. ${ }^{17}$ De aanpak had succes: in 1913 is het bedrijf een van de slechts vier ondernemingen die op de wereldtentoonstelling in Gent het

14. Idem, 16-18.

15. Idem, 19.

16. Idem, 17-18.

17. s.n. Usines Peters-Lacroix, Paris UPL, Usines Peters-Lacroix, (1883-1983)(Paris: UPL, 1983), 19. 
behangpapier vertegenwoordigde. ${ }^{18}$ De familie Peters-Lacroix getuigde bovendien ook van een opmerkelijke veerkracht en een grote sociale betrokkenheid waar het hun personeel betrof. Het was geen kil concern, maar een warm familiebedrijf. ${ }^{19}$

Tijdens de wereldoorlogen lag de productie stil, voornamelijk door gebrek aan grondstoffen en arbeidskrachten. Vooral papier was moeilijk te verkrijgen en arbeiders konden door de dienstplicht hun job niet uitvoeren. In 1918 pikte het bedrijf moeiteloos de draad weer op en ging een grote economische bloei tegemoet. In 1923 overleed Herman Peters, sinds jaren de drijvende kracht achter dit bedrijf; vijf jaar later stierf mevrouw Lacroix-Peters. ${ }^{20}$

\section{Uit de anonimiteit: Servranckx en Magritte}

De zonen en hun erven zetten het bedrijf op hetzelfde familiale elan verder en trokken daarenboven nieuwe, jonge kunstenaars aan, waaronder Victor Servranckx (1897-1965) en René Magritte (1898-1967), de enige ontwerpers aan wie enig ontwerp binnen dit bedrijf met zekerheid toegewezen kan worden. ${ }^{21}$ De twee kunstenaars bleven echter maar een paar jaar verbonden aan de Usines Peters-Lacroix. Voor hen bleek gedwongen ontwerp nefast voor hun creativiteit. Magritte verliet het bedrijf naar verluidt vol walging voor de decoratieve kunsten. ${ }^{22}$ In de jaren twintig kwam de avant-garde immers op tegen al te veel decoratie en daar sloten ook Servranckx en Magritte zich bij aan. ${ }^{23}$

18. 'Algemeene Wereldtentoonstelling Van Gent 1913. Bijzondere Ambtelijke Catalogus Der Belgische Afdeeling', (Brussel: Weissenbruch, 1913).

19. s.n. Usines Peters-Lacroix, Paris UPL, Usines Peters-Lacroix, (1883-1983)(Paris: UPL, 1983), 20.

20. Idem, 28 .

21. Jan Van den Eynde, 'Les Usines Peters-Lacroix (UPL),'22.

22. Marilyn Hapgood, Wallpaper and the artist. From Dürer to Warhol (New York, Londen, Parijs: Abbeville Press Publishers, 1992), 187.

23. Norbert Poulain, 'Belgisch behangselpapier uit het interbellum,' uitgegeven ter gelegenheid van de Open Monumentendag Vlaanderen 1996 en de tentoonstelling georganiseerd door interbellum in villa De Bondt, New Jewels gallery, Krijgslaan 124, Gent, van 7 to 29 september 1996, Interbellum, 1996, 5. 
De modernisten wisten niet wat ze met dat tijdelijke muurpapier aan moesten: camoufleerde het iets of toonde het zichzelf? ${ }^{24}$

Voor de fabriek brak het succes niet helemaal door: op de Exposition Universelle in Parijs in $1925 \mathrm{kreeg}$ de fabriek het verwijt niet innovatief genoeg te zijn. ${ }^{25}$ Het officiële rapport vermeldde: "Les cuvres exposées par les Usines Peters-Lacroix étaient abondantes, mais ne témoignent pas d'une grande nouveauté (...). ${ }^{126}$ De onbekende ontwerper Georges Darcy kreeg een eervolle vermelding en Libert-Ruff en Victor Servranckx een gouden medaille. ${ }^{27}$ Dit was een tegenslag, want op de wereldtentoonstelling van 1905 in Luik werd de fabriek nog een van de belangrijkste ondernemingen van België genoemd, door het feit dat ze volledig mechanisch te werk ging en ook bekend was voor het produceren van behangpapier met reliëf, wat een soort imitatie-goudleder was. ${ }^{28}$

\section{De laatste behangpapierfabriek in Brussel}

Tijdens de Tweede Wereldoorlog vernielden bommen een deel van de bedrijfsgebouwen en de rest werd door de bezetter in beslag genomen. Ook toen lag de fabriek stil door een gebrek aan mankracht en grondstoffen. Vooral steenkool en papier waren moeilijk te verkrijgen. ${ }^{29} \mathrm{De}$ bedrijfsleiding deed wat ze kon om de getroffen families van levensmiddelen te voorzien. In deze periode, in 1943, stierf Georges Lacroix op 71-jarige leeftijd. Herman Colson (1904-1963), een neef van Yvan Peters, volgde hem op. ${ }^{30}$

24. Norbert Poulain, idem, 5.

25. Françoise Marneffe, 'Les Usines Peters-Lacroix à Haren', 69.

26. Norbert Poulain, 'Belgisch behangselpapier', 7 .

27. Clouzot, Henri, and Ch. Follot,. Histoire Du Papier Peint En France (Paris: C. Moreau, 1935), 243-248.

28. Françoise Marneffe, 'Les Usines Peters-Lacroix à Haren,' 68, Lesley Hoskins, red. The papered Wall. History, Pattern, Technique (New York (N.Y.): Abrams, 1994),186.

29. s.n. Usines Peters-Lacroix, Paris UPL, Usines Peters-Lacroix, (1883-1983)(Paris: UPL, 1983), 28.

30. Jan Van den Eynde, 'Les Usines Peters-Lacroix (UPL),' 28. 
De oorlog had op alle gebieden heel wat gevolgen voor de maatschappij. Voor ontwerp en design betekende het een grote ommekeer. Door schaarste aan materialen en grondstoffen werd alle productie erg functioneel bekeken, vaak vanuit het principe van een existenzminimum. ${ }^{31}$ $\mathrm{Na}$ de oorlog werden de Usines Peters-Lacroix heropgestart met een focus op uitbreiding, door onder meer filialen in het buitenland op te richten. Frankrijk (Parijs) (zie afb. 4), Italië (Milaan), Nederland (Breda) en Duitsland (Aken) maakten van de UPL een bedrijf van wereldniveau. ${ }^{32}$ Ook het aantal producten werd opgevoerd: er werden ontwerpen van eigen makelij geproduceerd, maar ook in het buitenland aangekocht, tot zelfs buiten Europa, in Japan. ${ }^{33}$

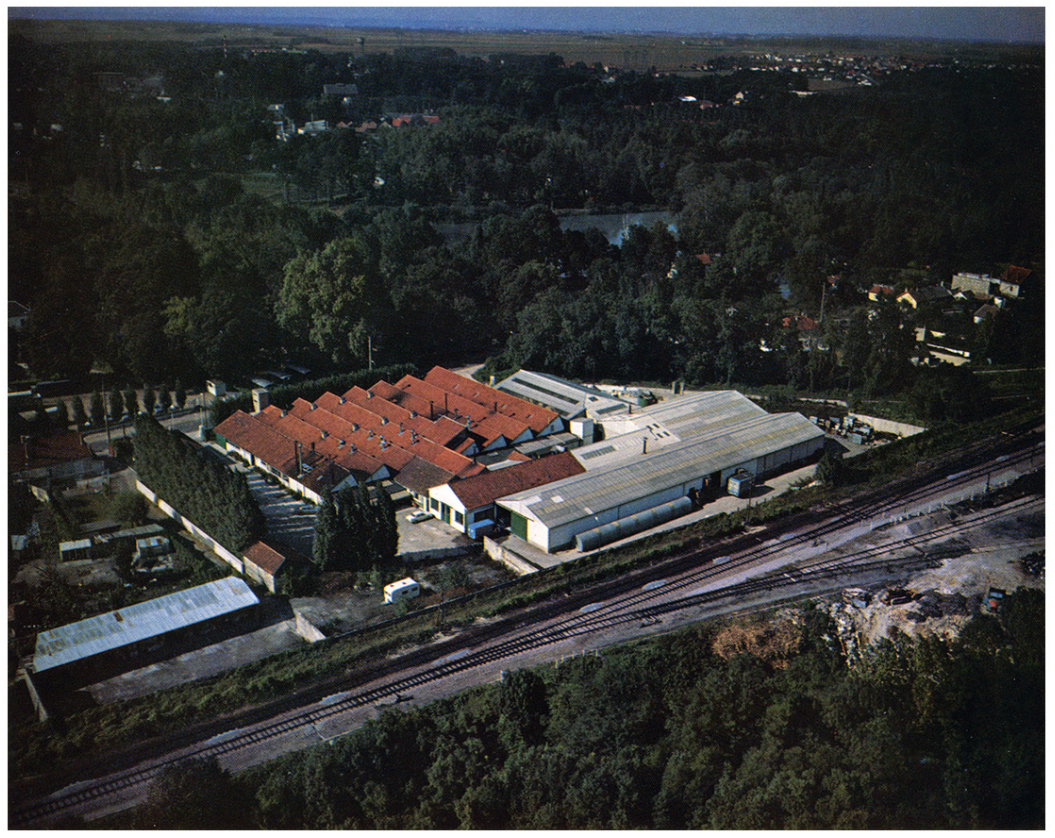

Afbeelding 4: De Franse fabriek in Ballancourt.

Bron foto: Usines Peters-Lacroix, (1883-1983), p. 120

31. Denis Laurent, 'Tussen idealisme en pragmatisme, de overgang naar volwassenheid,' in: Claire Leblanc, Art Nouveau E̋ Design. Sierkunst van 1830 tot Expo 58, (Tielt, Lannoo, 2005), 133.

32. Denis Laurent, idem, 28.

33. Jan Van den Eynde, 'Les Usines Peters-Lacroix (UPL),' 29. 
Jammer genoeg kwam er eind de jaren 70 een eind aan de bloei van de UPL, dat het enige nog werkende bedrijf was in Brussel. ${ }^{34}$ De buitenlandse concurrentie woog steeds zwaarder door..$^{35}$ Door wanbeleid en een aantal verkeerde beslissingen kwam het bedrijf in een negatieve spiraal terecht. ${ }^{36}$ De productie daalde en een subsidie van de overheid mocht niet meer baten. Op 20 juli 1979 werd de firma failliet verklaard. ${ }^{37}$

\section{Een humanitair bedrijf}

De Usines Peters-Lacroix was een familiebedrijf met oog voor de sociale leefomstandigheden van haar werknemers. ${ }^{38}$ De directie leverde grote inspanningen om het leven en werk in en buiten de fabriek voor de arbeiders aangenaam te maken. Zo werd er in 1921 een hulpkas opgericht voor wie het moeilijk redde en werd verlof betaald. In 1924 werd de pensioens- en invaliditeitskas opgericht en in $1953 \mathrm{kwam}$ er een kinderfonds dat ervoor zorgde dat de werknemers en hun gezin jaarlijks met vakantie konden. Vanaf 1921, de jaren na de Eerste Wereldoorlog, ijverde het bedrijf ook sterk voor het bouwen van arbeiderswoningen. Deze bevinden zich nu nog steeds in de Blijde Inkomststraat en omliggende straten in Machelen. ${ }^{39}$ Ook in de latere jaren getuigde het bedrijf van een zin voor het sociale: een blije medewerker is een gemotiveerde medewerker, moet men gedacht hebben. Er werd veel voor de medewerkers en hun kinderen georganiseerd. $Z_{o}$ waren er sporttornooien, een voetbalploeg (zie afb. 5), toneelvoorstellingen en sinterklaasvieringen op kosten van het bedrijf. ${ }^{40}$ In vroegere jaren getuigde ook Georges Lacroix van een sociaal engagement. Hij deed schenkingen aan het OCMW en steunde de Maatschappij der

34. Françoise Marneffe, 'Les Usines Peters-Lacroix à Haren, 69.

35. Françoise Marneffe, 'Les Usines Peters-Lacroix à Haren, 70.

36. Stéphane Duquesne, e-mail.

37. Jan Van den Eynde, 'Les Usines Peters-Lacroix (UPL), 22.

38. Françoise Marneffe, 'Les Usines Peters-Lacroix à Haren,' 71.

39. Jan Van den Eynde, 'Les Usines Peters-Lacroix (UPL),' 22.

40. s.n. Usines Peters-Lacroix, Paris UPL, Usines Peters-Lacroix, (1883-1983)(Paris: UPL, 1983), 111. 
Goedkope Woningen. Na zijn overlijden werd een straat in Machelen naar hem vernoemd. ${ }^{41}$

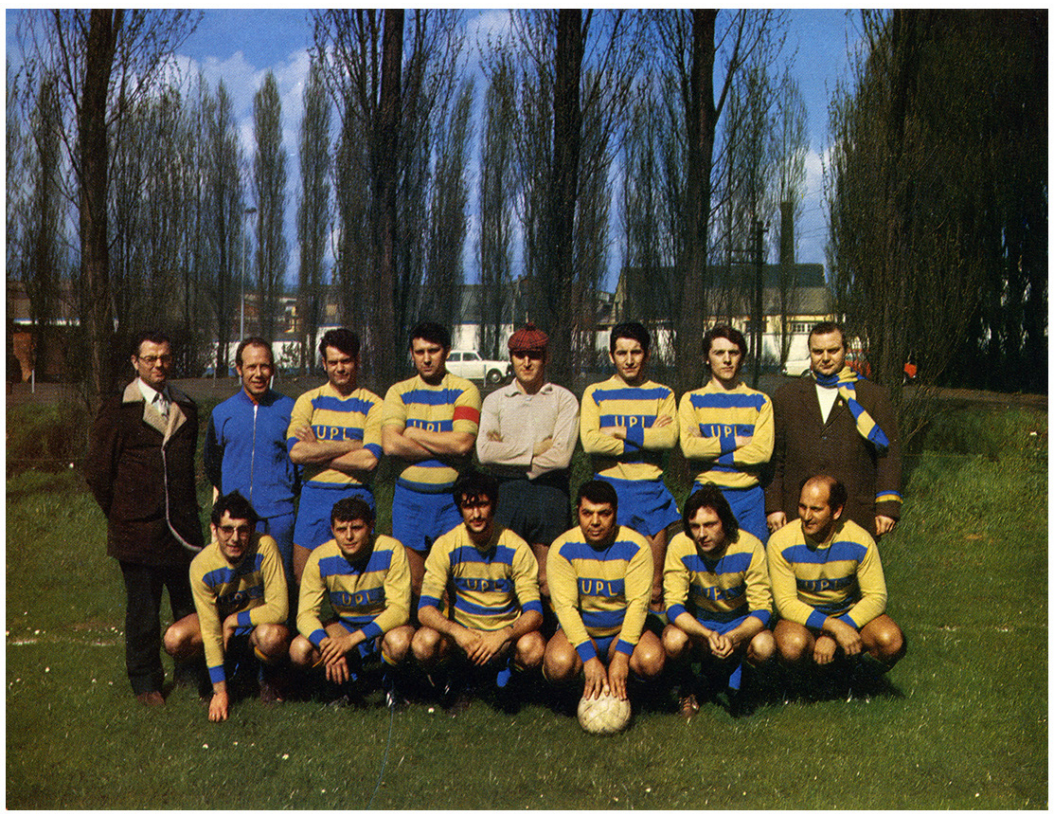

Afbeelding 5: De voetbalploeg van UPL in 1971-72. Bron foto: Usines Peters-Lacroix, (1883-1983), p. 115

\section{Pierre Duquesne, ontwerper / kunstenaar}

Pierre Duquesne werd op 5 november 1925 in Diegem geboren als zoon van Fernand Duquesne en Alice Hazaert. Hij was het vierde kind in een rij van tien, vijf broers en vier zussen. Fernand Duquesne was personeelsverantwoordelijke en financieel directeur in een staalbedrijf in Haren. Het milieu waarin Pierre opgroeide, was intellectueel. Er was interesse voor wetenschap, literatuur en klassieke muziek. Ondanks de moeilijke levensomstandigheden tijdens de Tweede Wereldoorlog, konden alle kinderen zonder studiebeurs toch een degelijk diploma behalen. Pierre was de enige die voor een kunstzinnige opleiding koos, zijn broers en zussen opteerden voor meer zakelijke

41. Jan Van den Eynde, 'Les Usines Peters-Lacroix (UPL),'22. 
carrières: burgerlijk ingenieur, boekhouder, regentes, piloot, dokter en laborant. ${ }^{42}$

De jonge Pierre volgde basisonderwijs in de gemeenteschool van Diegem, om van daaruit naar het Sint-Mariacollege in Schaarbeek te trekken. Daar voelde hij zich echter in een keurslijf gewrongen en hij veranderde op 15-jarige leeftijd naar de Sint-Lucasschool in Schaarbeek, een kunsthumaniora. Voor hem was dit kunstzinnige milieu een openbaring en hij voelde zich eindelijk op zijn plaats. $\mathrm{Na}$ de middelbare school koos hij dan ook voor de kunsten en trok naar Sint-Lucas in Brussel-Schaarbeek. Daar haalde hij op 15 juli 1946 cum laude zijn diploma Grafische Kunsten.

In Sint-Lucas kreeg hij les van onder meer beeldhouwer Harry Elstrøm (1906-1993) ${ }^{43}$ en kunstenaar-broeder Emiel Vandermosten (1893-1994).44 Tegelijkertijd volgde hij ook bijkomende lessen aan het vermaarde Ter Kameren Instituut in Brussel, onder leiding van Herman Teirlinck (1879-1967) ${ }^{45}$ en onder andere Charles Counhaye (1884-1971). ${ }^{46}$ Hij volgde daarnaast ook de vrije tekenateliers bij Edgard Tytgat (1879-1957), ${ }^{47}$ in een molen in Sint-LambrechtsWoluwe, samen met andere kunstenaars, waaronder bijvoorbeeld Maurits Verbist (1913-1984)..8 Ook Edgard Tytgat werkte als

42. Stéphane Duquesne, e-mail met bijlage.

43. "Basilica Koekelberg," laatst geraadpleegd op 19 mei 2018. http://www.basilicakoekelberg.be/documents/basilica/the-monument/sculptures/harry-elstrom. $\mathrm{xml}$ ?lang=nl

44. "Digitale bibliotheek voor de Nederlandse letteren", laatst geraadpleegd op 19 mei 2018, http://www.dbnl.org/tekst/_vla016197601_01/_vla016197601_01_0051. php.

45. "Huis van Herman Teirlinck," laatst geraadpleegd op 19 mei 2018, http://www. huisvanhermanteirlinck.be/over-herman-teirlinck/

46. "Charles Counhaye," laatst geraadpleegd op 19 mei 2018, https://rkd.nl/nl/ explore/artists/Counhaye\%2C\%20Charles.

47. "Edgard Tytgat", laatst geraadpleegd op 20 mei 2018, https://www.mleuven. be/nl/tytgat.

48. Guido Sys, "Maurits Verbist, de laatste volbloed Vlaamse expressionist." Laatst geraadpleegd op 19 mei 2018. https://herentblog.files.wordpress.com/2010/04/verbist-brosjure-lr.pdf 
ontwerper voor een behangpapierfabriek, maar hoewel sommige bronnen hierbij naar UPL verwijzen is dat niet bewezen. ${ }^{49}$ Andere bronnen wijzen naar andere Brabantse fabrieken, onder meer naar de familie Vanderborght. ${ }^{50}$ Duquesne liet al in zijn opleiding merken dat hij oog had voor kunst en toonde een gedrevenheid om te creëren, zonder zich daarbij op de voorgrond te dringen. ${ }^{51}$

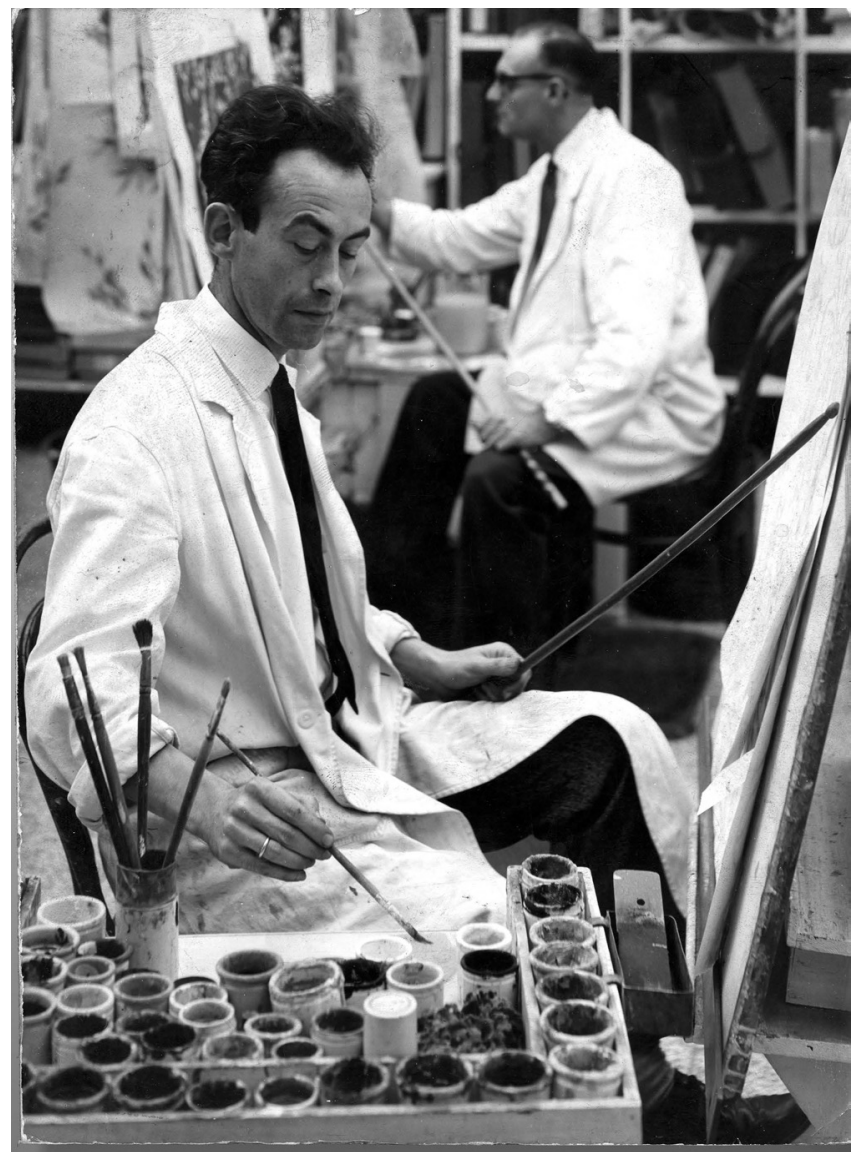

Afbeelding 6: Pierre Duquesne in het atelier van UPL. Bron foto: A.S.B., Sectie Privéarchief, Particuliere archieven, Archives Pierre Duquesne, n¹228_11.

49. "Edgard Tytgat," laatst geraadpleegd op 19 mei 2018, http://www.odis.be/hercules/toonPers.php?taalcode=nl\&id=13579.

50. Daelemans en Wisse, Voor de geschiedenis van papierbehang. Bronnen en methoden, 12. Onuitgegeven lesnotities.

51. Stéphane Duquesne, e-mail met bijlage. 
Als graficus was het geen sinecure voor Pierre om een job te vinden. Hij vond betrekkingen in de reclamewereld, maar kreeg uiteindelijk een job aangeboden bij de Usines Peters-Lacroix in Haren, waarvan Lucien Rijs-Peters, zijn schoonbroer, aandelen bezat. ${ }^{52} \mathrm{Hij}$ ging als ontwerper van behangpapieren (zie afb. 6) bij UPL aan de slag in 1947 tot 1979, toen de fabriek failliet ging. De laatste tien jaar van zijn carrière was hij artistiek directeur en besliste zo dus mee over de keuze voor bepaalde designs en tendensen van het behangpapier. In 1960 huwde hij met Clara De Mortier, die ook uit Diegem afkomstig was. Uit deze relatie werd in 1963 een zoon geboren: Stéphane Duquesne. Het gezin woonde toen in de Woluwestraat 138 in Diegem en om praktische redenen werd in deze bungalow alles op het gelijkvloers gebouwd. In het gezin woonde ook de vader van Clara De Mortier in, Karel De Mortier, die voor onbepaalde tijd bedrijfsarts was bij werkongevallen in de fabrieken van de UPL. ${ }^{53}$

\section{Van ontwerper naar artistiek directeur}

De loopbaan van Pierre Duquesne bij de UPL startte in 1947. Hij werd dan aangeworven als ontwerper van behangpapier in het tekenatelier in Haren. Gedurende 32 jaar zou hij deze job uitoefenen. Rond 1970 werd hij artistiek directeur van het ontwerpersteam (zie afb. 7). In 1972 ontving hij eretekens voor 25 dienstjaren bij de zaak door de heer Paul Van Mollekot, directeur en aangetrouwde kleinzoon van de familie Peters-Lacroix. ${ }^{54}$ Pierre Duquesne werkte in het bedrijf in een team van tekenaars, met onder andere Darci, Van Assche, Malcorps en Moerenhout. ${ }^{55}$

52. Addendum bij de catalogus "Pierre Duquesne, artiste-kunstenaar 1925-2003".

53. Idem.

54. Idem.

55. Idem. 


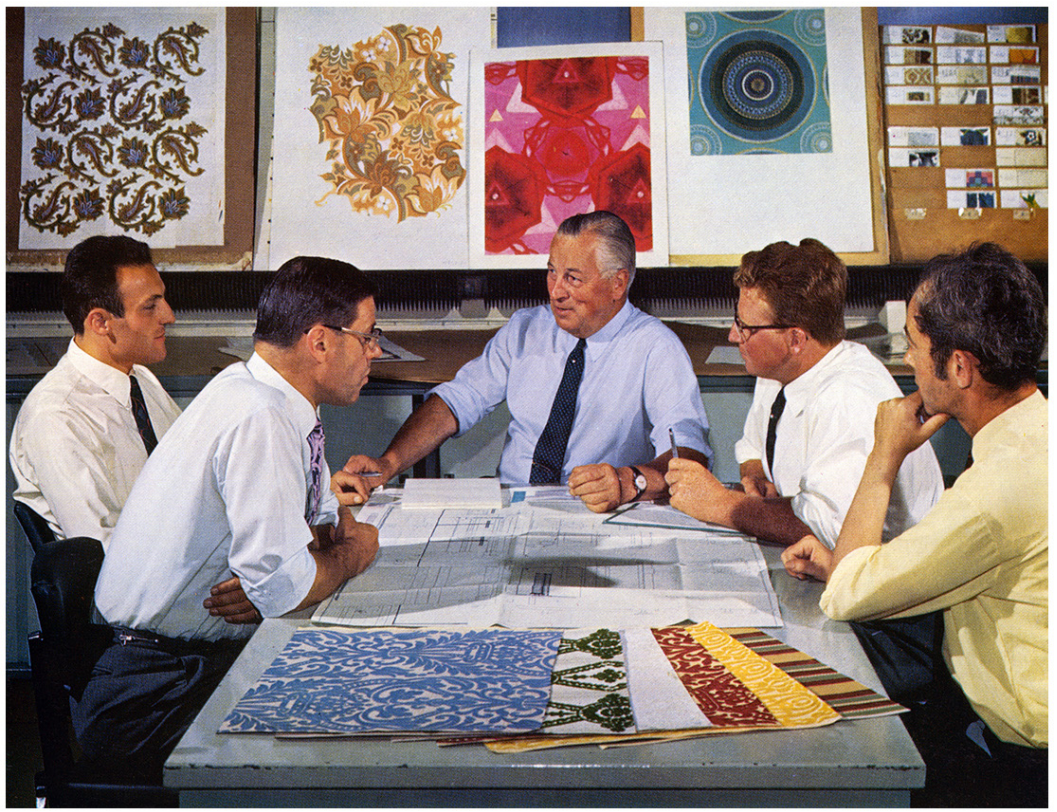

Afbeelding 7: Het artistiek en technisch comité bij UPL, onder leiding van Pierre Lacroix. Rechts onder zit Pierre Duquesne.

Bron foto: Usines Peters-Lacroix, (1883-1983), p. 101

Het ontwerpen van behangpapier was geen sinecure. Een korte schets van de manier van werken binnen dit bedrijf verduidelijkt waarom. Het eerste stadium was het bepalen van de modellen waarmee gewerkt zou worden. Deze creaties werden in huis gemaakt of in het buitenland aangekocht en aangepast aan de behoeften van de markt. ${ }^{56}$

Vervolgens gingen deze goedgekeurde tekeningen naar een volgende ploeg van tekenaars, die ze moesten doortrekken of 'calqueren' voor het graveren van de cilinders. In een volgende fase werden deze calques gereproduceerd op de drukcilinders aan de hand van een vrij technisch fotografisch proces. De machines hiervoor waren erg innovatief en gespecialiseerd. De tekeningen werden vervolgens gegraveerd, een tijdrovend en precies werk. Deze techniek werd door hoogopgeleide

56. s.n. Usines Peters-Lacroix, Paris UPL, Usines Peters-Lacroix, (1883-1983)(Paris: UPL, 1983), 37-97. 
vaklui uitgevoerd en werd de ingeplante gravuur genoemd. Uit economische overwegingen werd deze techniek vooral machinaal uitgevoerd. De gegraveerde cilinders tenslotte bewaarde men in kluizen, want zij waren essentieel in het proces van drukken. ${ }^{57}$

Aan gigantische containers met witte verf werden pigmenten toegevoegd om zo een heel gamma aan kleuren te verkrijgen. Voor het effectieve bedrukken van het papier bestonden heel diverse machines: grondeermachines om een grondlaag aan te brengen, duplex-gauffreermachines die een reliëf konden creëren en 2- tot 16-kleurige persen. Het behangpapier werd in grote rollen bedrukt, gedroogd en tenslotte tot standaardrollen versneden en in dozen verpakt. ${ }^{58}$

Deze manier van werken was voor kunstenaars zowel remmend als stimulerend. Zo getuigde Victor Servranckx in een interview met Joos Florquin op 29 september 1961, dat een tekening versneden werd om weer opnieuw gebruikt te worden en dat principe paste hij ook op zijn collages toe. Ook het nummeren van de tekeningen nam hij vanuit het ontwerpen van behangpapieren over. ${ }^{59}$ Uit het interview blijkt ook de haat-liefdeverhouding hij als kunstenaar met dit werk had:

"Ik heb er schrikkelijk veel geleerd. Ik heb daar ook het atelier voor tekenaars gedirigeerd. Ik was antidekoratief gezind en zat daar in volle sierkunst. Ik heb daar ook geleerd wat een muur is, want het motief op het behang moest altijd muraal blijven. Maar mijn kunst zelf stond vreemd tegenover die aktiviteit, die voor mij een leugen was. ${ }^{160}$

57. Idem, 37-97.

58. s.n. Usines Peters-Lacroix, Paris UPL, Usines Peters-Lacroix, (1883-1983)(Paris: UPL, 1983), 37-97.

59. "Ten Huize van 5", interview door Joos Florquin met Victor Servranckx op 29 september 1961. "Digitale bibliotheek voor de Nederlandse letteren." Laatst geraadpleegd op 20 mei 2018. http://www.dbnl.org/tekst/flor007tenh05_01/flor007tenh05_01_0008.php.

60. "Ten Huize van 5." 
Robert Boudru werkte bij een andere bekende manufactuur, de Papeteries de Genval. Hij getuigde ook over het moordende tempo van het werk, dat het uiterste vergde van de ontwerpers:

"Au studio, on créait des dessins avec des colorations: 400 à 450 références nouvelles chaque année, soit 100 à 120 dessins différents dans de larges gammes de prix. À côté de nos propres productions, nous importions aussi des produits d'autres usines, notamment anglaises. Cela nous permettait de distribuer des produits que Genval ne savait pas produire. ${ }^{161}$

De schenking van Robert Boudru aan het Design Museum in Gent bewijst dat hij zich als ontwerper heel goed bewust was van wat er geproduceerd werd door de andere bedrijven, zoals onder de Usines Peters-Lacroix. ${ }^{62}$

Net als Boudru en Ryelandt en veel andere anonieme ontwerpers stond Pierre Duquesne aan het begin van het productieproces. Het ontwerpen van behangpapier was tijdrovend, geconcentreerd werk en heel vermoeiend voor de ogen. Ook op creatief gebied vergde dit het uiterste van een ontwerper. Het werk moest immers steeds vernieuwend blijven en marktbestendig. Later, toen het bedrijf haar monopolie ook in het buitenland probeerde te vestigen, werd er ook vergaderd in de verschillende filialen. ${ }^{63}$ Pierre Duquesne ging dan ook vaak naar de afdelingen in Parijs of in Hamburg, waar het bedrijf een samenwerkingsverband had voor een speciaal soort gravure, de rotagravure. ${ }^{64}$

61. Françoise Marneffe en Silvie Lefebvre, 'Rencontre avec Robert Boudru et Léopold Ryelandt, stylistes du papier peint,' in: les Cahiers de la Fonderie, Bruxelles Hier, nr. 41; (Bruxelles industrielles hier, december 2009), 72.

62. Designarchief, Schenking Robert Boudru en Arte.

63. Addendum bij de catalogus "Pierre Duquesne, artiste-kunstenaar 1925-2003, bijlage II.

64. De rotascreen-machines kwamen tot stand door een samenwerking tussen UPL, J. Zimmer en E. Pagendarm. Deze machines kunnen 300 meter behangpapier per minuut bedrukken. Usines Peters-Lacroix, 37-97. 
Alle ontwerpen bleven anoniem, behalve de ontwerpen die door Servranckx en Magritte worden gemaakt (zie supra). Pierre Duquesne bracht af en toe een staal waaraan hij had gewerkt mee naar huis om aan zijn vrouw en zoon te laten zien, maar dit was eigenlijk ongebruikelijk en het ontwerp moest de dag nadien al terug naar het bedrijf. Zoals op de foto te zien is, droegen de werknemers lange tijd witte schorten. $Z$ ij gebruikten ook een lange stok om hun arm en hand te ondersteunen bij het precisiewerk. ${ }^{65}$

In de jaren 70 werkte het bedrijf met een ploegensysteem bij het ontwerpersteam. Er was een ploeg van 6 uur tot 14 uur en een tweede ploeg van 14 uur tot 22 uur. Het werk was vermoeiend en zorgde voor stress. Toch was Pierre Duquesne ondanks het vermoeiende werk altijd trots op wat hij deed. Op vakantie logeerde hij met zijn gezin vaak in hotels waarvan de kamers waren behangen met 'zijn' behangpapier. ${ }^{66}$ Pierre volbracht zijn taak met passie, ongeacht alle beperkingen die het zijn creatieve ziel opleverde. In 1974 onderging hij een openhartoperatie. Tijdens zijn herstelperiode werd hij gesteund door zijn oversten en directe bazen. ${ }^{67}$ In 1979 sloot het bedrijf definitief de deuren. Pierre Duquesne werd hierdoor met vervroegd pensioen gesteld. $^{68}$

65. Addendum bij de catalogus "Pierre Duquesne, artiste-kunstenaar 1925-2003, bijlage II.

66. Addendum bij de catalogus "Pierre Duquesne, artiste-kunstenaar 1925-2003, bijlage II.

67. Idem. Stéphane Duquesne, e-mail op 23 mei 2018.

68. Idem. 


\section{Kunstenaar in Diegem}

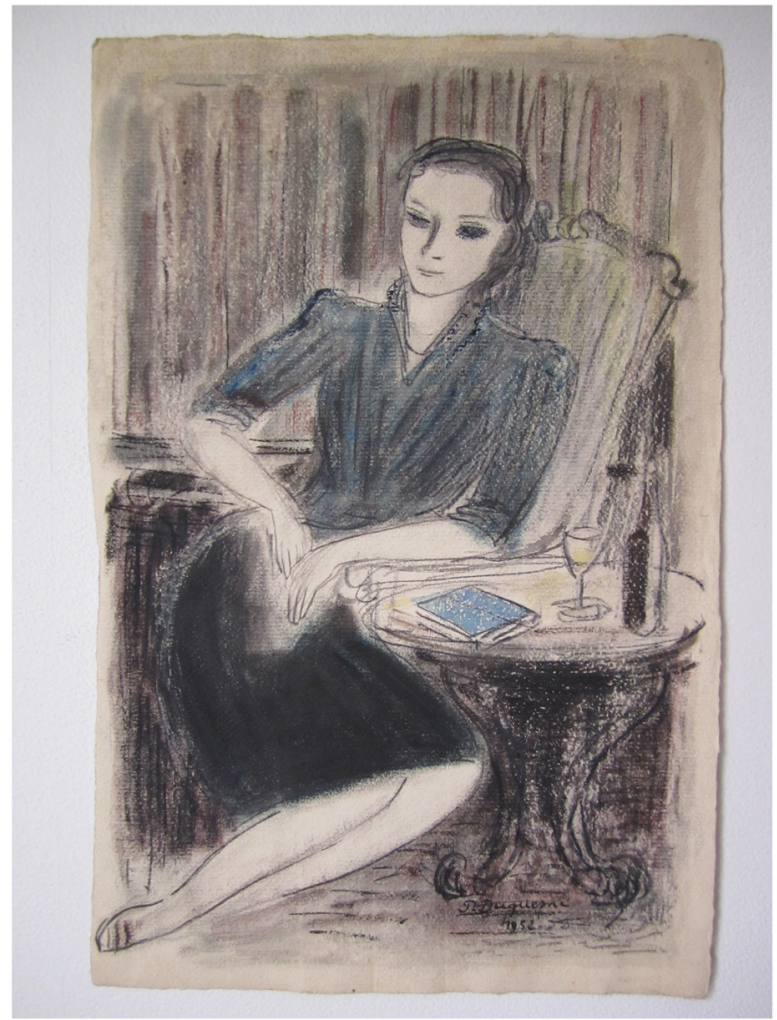

Afbeelding 8: Pierre Duquesne: "Clara De Mortier." Schets op papier met pastel. Bron foto: A.S.B., Sectie Privéarchief, Particuliere archieven, Fonds Pierre Duquesne, n'229.

Duquesne was na zijn werkuren gepassioneerd kunstenaar. Hij maakte schilderijen, tekeningen en karikaturen en ook beeldhouwwerken. In de catalogus, opgesteld door zijn zoon, zien we meer dan duizend verschillende werken van verschillend allooi: aquarel, olieverf, pastel, potlood- of pentekening. ${ }^{69}$ Zijn grootste muze was zijn vrouw, Clara De Mortier (zie afb. 8 en 9). Van haar staan in de catalogus talloze tekeningen en schilderijen. Hij schilderde in een atelier aan

69. Stéphane Duquesne, 'Pierre Duquesne. Artiste-kunstenaar, 1925-2003,' catalogus + addendum bij de catalogus. 
huis of deed en plein air inspiratie op. Hij schetste landschappen en natuur en bracht die dan nadien thuis op een doek over. ${ }^{70}$ Pierre Duquesne leerde het vak onder leiding van degelijke leermeesters en bestudeerde oude en nieuwe meesters. Hij was een groot bewonderaar van het werk van Michelangelo, Rembrandt, Rodin, Modigliani, Van Gogh, Monet, Rops, Evenepoel, Rik Wouters, Kees Van Dongen en Spilliaert. ${ }^{71}$ Hij kenmerkte zich door een erg uiteenlopende stijl: hij specialiseerde zich niet in één discipline, maar werkte met diverse materialen en diverse technieken, zoals klei, hout, houtskool, potlood, olieverf, aquarel en balpen. Voor hem stond kijken naar iets gelijk aan het in beeld brengen ervan: hij keek met zijn handen en vond overal inspiratie: dieren, personen, landschappen, decoratie, geen onderwerp was hem vreemd. ${ }^{72}$

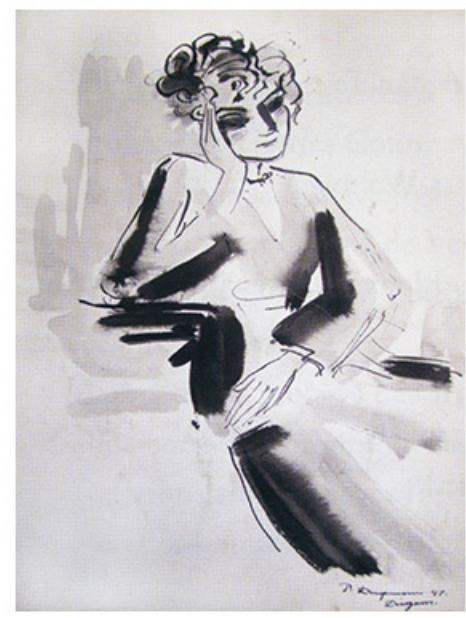

Afbeelding 9: Pierre Duquesne. "Clara De Mortier". Aquarel. Bron foto: A.S.B., Sectie Privéarchief, Particuliere archieven, Archives Pierre Duquesne, n¹233.

$\mathrm{Na}$ de kantooruren werkte hij aan zijn kunst en vanaf 1979, na de sluiting van de fabriek fulltime. Maar ook tijdens de jaren bij UPL

70. Stéphane Duquesne, 'Pierre Duquesne. Artiste-kunstenaar, 1925-2003,' catalogus + addendum bij de catalogus.

71. Idem.

72. Stéphane Duquesne, e-mail met bijlage. 
was zijn talent gekend: in tal van de uitgaven van het bedrijf zijn schetsen en karikaturen van Pierre Duquesne te vinden. ${ }^{73}$ Vooral bij pensionering van collega's werd van hem soms een persoonlijke schets gevraagd. ${ }^{74}$

Opvallend is ook dat zijn werk voor het ontwerp van behangpapier heel vaak erg abstract was, terwijl zijn eigen werk dan weer vooral figuratief. Misschien was dit een bewuste keuze, om het een van het ander te scheiden? Het ontwerpen van behangpapier was echter vaak erg beperkt: veel vrijheid kregen de tekenaars niet: zij moesten rekening houden met marktwaarde en opgelegde instructies. Zijn eigen kunst was het tegenovergestelde: daar moest hij met niemand rekening houden. Mogelijk had hij dezelfde ervaring als onder andere Servranckx, die uit zijn werk als ontwerper ook elementen overnam in zijn eigen werk. ${ }^{75}$

In de loop van zijn carrière vonden een aantal tentoonstellingen van zijn werk plaats, al was hij geen man die het voetlicht opzocht. Zo stelt hij in Au Cheval de Verre in Brussel tentoon in 1969. Onder meer de weduwe van Edgard Tytgat is op de opening aanwezig (afb. 10). ${ }^{76}$ Daarnaast was er ook in het Cultureel Centrum van Affligem/ Hekelgem een tentoonstelling van zijn werk van 14 tot 30 november 1969. ${ }^{77}$ En in 1989 organiseerde de gemeente Diegem tussen 8 en 17 september in het Cultureel Centrum van Diegem een expositie van zijn werk. ${ }^{78} \mathrm{Zijn}$ werk werd lokaal gesmaakt, wat blijkt uit een aantal

73. Archief Pierre Duquesne, 'Magazine uitgegeven voor UPL,' Archief Stad Brussel, Collection des archives privées, 1225-1233.

74. Stéphane Duquesne, e-mail met bijlage.

75. "Ten Huize van 5", interview door Joos Florquin met Victor Servranckx op 29 september 1961. "Digitale bibliotheek voor de Nederlandse letteren." Laatst geraadpleegd op 20 mei 2018. http://www.dbnl.org/tekst/flor007tenh05_01/flor007tenh05_01_0008.php.

76. Archief Pierre Duquesne, Archief Stad Brussel, ASB, Collection des archives privées, 1225-1233.

77. Idem.

78. Idem. 
positieve recensies in de krant, onder andere Le Soir, La Dernière Heure en La Libre Belgique. ${ }^{79}$

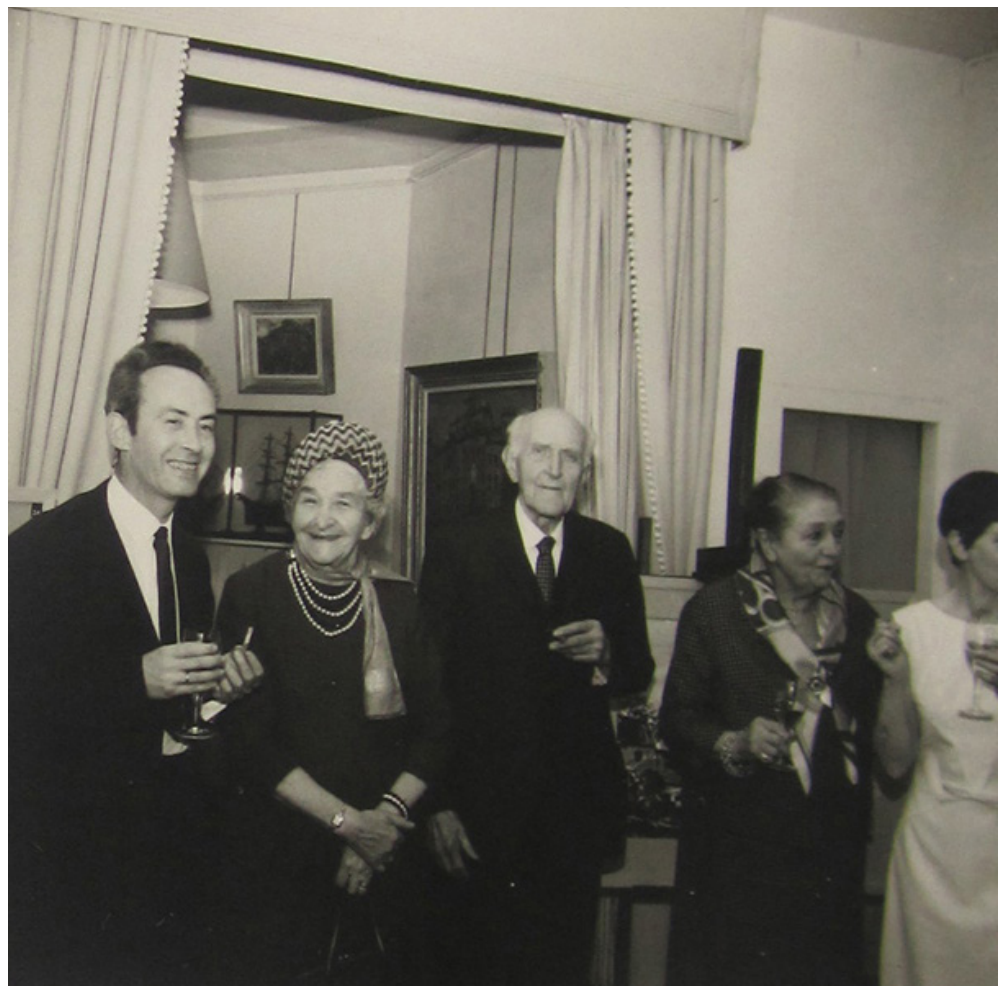

Afbeelding 10: Pierre Duquesne met mevr. Tytgat op de opening van zijn tentoonstelling in 1969. Bron foto: A.S.B., Sectie Privéarchief, Particuliere archieven, Archives Pierre Duquesne, n¹231_24.

Gilbert Putteman, lokaal kunstcriticus en bezieler van de tentoonstelling in 1989, schreef in het voorwoord in de brochure de volgende lovende woorden:

"Pierre Dusquesne is iemand die naar métierschap streeft en dit ongeacht of het een aquarel, gouache, schilderij, tekening of schets betreft.

79. Idem. 
Hij slaagt erin om op zeker sobere, soms zelfs ironische wijze uiting te geven aan zijn gevoelens. ${ }^{180}$

Het sterkt de visie dat deze man voor alles voor zijn métier leefde, zowel op gebied van zijn werk als in zijn eigen kunst.

Pierre Duquesne was een man die zijn aandacht verdeelde tussen zijn toewijding voor zijn werk als ontwerper bij de Usines Peters-Lacroix en zijn drang tot het creëren van eigen kunstwerken. Als personeelslid bij de UPL ontwierp hij behangpapier en besliste als bestuurslid van het artistiek team voor een stuk mee over de koers die de fabriek voer. Als getuige van zijn werkzaamheden bij een historisch waardevol bedrijf treedt hij hierdoor voor een stuk uit de anonimiteit. In deze zin is hij een klein, doch relevant onderdeel van het historisch onderzoek naar en de studie van het behangpapier in België.

80. Archief Pierre Duquesne, "Brochure bij de tentoonstelling in 1989," Archief Stad Brussel, ASB, Collection des archives privées, 1225-1233. 